\title{
Editorial
}

\section{Public health issues in Hong Kong and China}

On 1 July 1997, Hong Kong was returned to China after having been under British administration for over 100 years. The return of Hong Kong to China opens a new horizon and provides opportunities and challenges in the various areas of public health. After the opening of China to the outside world, there have been tremendous developments in the country, particularly in industry, business enterprises, and property development. Many rural people from the inner and less developed provinces in China have flocked to the cities to seek employment.

As a result of these rapid developments, many new public health problems have emerged. These include environmental hygiene and sanitation, pollution of the environment and water sources as well as food contamination. The problem of disposal of industrial and toxic waste has become a serious concern. Some factories have a poor standard of occupational hygiene and safety. Occupational injuries are on the increase and there have been reports of acute chemical poisoning among workers in toy production factories. ${ }^{1}$ Mental health, school hygiene, and injuries arising from traffic and industrial accidents have become more and more obvious.

In Hong Kong, a number of major outbreaks of infectious diseases have occurred in recent years. These include outbreaks of cholera, viral hepatitis A, food poisoning, and influenza $\mathrm{A}\left(\mathrm{H}_{5} \mathrm{~N}_{1}\right){ }^{2-4}$ There has also been resurgence of tuberculosis and malaria. Apart from HIV/AIDS, a new strain of Escherchia coli-O157 $\left(\mathrm{H}_{7}\right)$ has been detected in samples of beef in 1997.

Apart from environmental health issues, other important common factors affecting the health of population in China and Hong Kong have also emerged. These factors are social, economic, and behavioural. Their impact is particularly felt on the chronic diseases. Aging of the population, changes in the socioeconomic environment, changes in lifestyle, smoking, excess alcohol consumption and drug abuse, all together account for a large proportion of chronic diseases. $^{5}$

The subject of smoking is particularly worrying. The smoking rate among adults in China is reported to be over $30 \%$ and in Hong Kong $15 \%{ }^{6}$ There is an increasing proportion of young men and young women taking up smoking. ${ }^{7}$ The age at which children started to smoke was getting younger. The WHO estimated that deaths from tobacco use will increase from the current figure of 3 million per year worldwide to 10 million by the year $2025 .{ }^{8}$ It is predicted that at least 2 million of these 10 million deaths will take place in China alone. The tobacco settlements recently reported to have taken place in the United States between the tobacco industries and the US Government is causing great concern to the developing countries, as the multi-national tobacco industries are likely to push hard to open new markets in the Asia-Pacific region to make up for the loss of revenue at home.

Another public health issue is the increase in sexually transmitted diseases (STD). The increase in volume of travel between Hong Kong and mainland China, especially the daily movement of a huge number of truck drivers across the border facilitates the spread of STD and HIV/AIDS. ${ }^{9}$

\section{What lessons have been learned from these emerging public health issues?}

Hong Kong depends a lot on the neighbouring provinces in mainland China for the supply of food and water. The extensive urbanisation and industrialisation in the rural counties and villages of China have resulted in many problems of environmental pollution, food contamination, and pollution of water sources. Hong Kong has experienced many outbreaks of food poisoning caused by imported vegetables contaminated with agricultural pesticides. ${ }^{10}$

The standard of environmental hygiene and food hygiene in Hong Kong has been declining as reflected by the occurrence of many outbreaks of the gastrointestinal group of infectious diseases. ${ }^{11}$ At the same time, aging of the population, changes in lifestyle and behaviour are responsible for the increase in chronic diseases.

\section{What are the opportunities and challenges in tackling these public health issues?}

Firstly, the return of Hong Kong to China opens up a large area of collaboration between Hong Kong and mainland China in joined research on medicine and public health subjects of common interest. Secondly, it will encourage more education and training programmes to be organised jointly for health care workers from Hong Kong and mainland China. ${ }^{12}$ Thirdly, it will strengthen the cross border cooperation in the prevention, control, and surveillance of infectious diseases and in environmental protection. Fourthly, it will also open the way for joined activities in dealing with common public health issues such as smoking, HIV/AIDS, and tuberculosis control. Close liaison and contact between non-governmental organisations and professional bodies in mainland China and Hong Kong is now well established and joint activities in research, conferences, seminars are on the increase. These opportunities are not just confined to the organisations in Hong Kong, they are also open to interested parties from overseas countries.

The first challenge ahead is how to secure commitment from governmental agencies and ministries in providing policy support and resources to implement the new activities. The present climate of economic recession is likely to hamper the speed of implementation of the new public health programmes. The second challenge is how to mobilise the community to take the initiative to improve community health. New models of community involvement such as "Healthy Cities", "Health Promoting Schools", and "Healthy Living" should be promoted The third challenge is how to enlist the support and cooperation of other sectors such as housing, environment, transport, education, agricultural and fishery in improving the health of the community. Although the responsibilities of these sectors are not directly related to health, their contributions to health are enormous. The fourth challenge is the need to revamp the existing outdated organisational structure of governmental agencies in dealing with environment health and food safety so that it can handle the new public health problems efficiently. ${ }^{13}$ 
Unless these issues are given top priority by government and urgently tackled, they will probably remain the major challenges to the public health professionals in the $21 \mathrm{st}$ century.

LEE SHIU-HUNG

Department of Community and Family Medicine, The Chinese University of Hong Kong, 4/F Lek Yuen Health Centre, Shatin, Hong Kong

1 Chau KL. Occupational health in special economic region. Beijing: Modern Occupational Health, People's Health Publication, 1994:661-5.

2 Lee SH. Prevention and control of communicable diseases in Hong Kong. Hong Kong: Government Printer, 1994.

3 Choi S, Tseung T. An update of influenza A (H5N1) in Hong Kong. Hong Kong: Public Health and Epidemiology Bulletin Hong Kong Department of Health, Feb 1998. Vol 7, no 1.

4 Lee SH, Lai ST, Lai JY, et al. Resurgence of cholera in Hong Kong. Epidemiol Infect 1996;117:43-9.

5 Public Health Report No 1. Coronary heart diseases and lung cancer. Hong Kong: Department of Health, 1994:19-44.
6 Mackay J. Country review in the Asia-Pacific region. Proceedings of the Third Asia-Pacific Conference on Tobacco or Health. The Asia Pacific Association for Control of Tobacco, 1993:12-19.

7 Lam TH, Chung, SF, Wong CM. The Youth Smoking and Health Survey 1994. Hong Kong: Hong Kong Council on Smoking and Health, Report No 1 .

8 Action Plan on Tobacco or Health for 1995-1999. Manila: WHO Regional Office for the Western Pacific, 1995.

9 Lo KK. A summary of major sexually transmitted diseases in Hong Kong. Hong Kong: Public Health and Epidemiology Bulletin, Hong Kong Department of Health, Feb 1994. Vol 3, no 1.

10 Leung PY, Wong M. Food poisoning in Hong Kong 1992. Hong Kong: Public Health and Epidemiological Bulletin, Hong Kong Department of Health, Nov 1993. Vol 2, no 4.

11 Leung PY, Tam S. Food safety Control in Hong Kong. Hong Kong: Public Health and Epidemiology Bulletin, Hong Kong Department of Health, Nov 1994. Vol 3, no 4

12 Lee SH, Lee JCK. Mainland China, Taiwan and the Hong Kong Region the Second Medical Education Conference. Med Educ 1997;31:468-72.

13 Hong Kong Special Administrative Region Government. Review of District Organizations. Hong Kong: Consultation Document June 1998. 